\title{
Zaratustra versus Parsifal
}

\author{
Stefano Busellato*
}

\begin{abstract}
Resumo: Entre os motivos que conduziram Nietzsche à escrita de Assim falou Zaratustra, os estudos especializados deixaram de investigar a importância que Wagner teve no surgimento dessa obra e, particularmente, o seu Parsifal. O presente artigo pretende evidenciar o conjunto dos elementos que permitem sustentar a hipótese de que, entre essas duas obras, há uma profunda relação. Relação que, quando trazida à luz, fornece enfoques exegéticos tão originais quanto úteis para uma mais penetrante compreensão de um texto que, sob muitos aspectos, apresenta-se altamente enigmático.
\end{abstract}

Palavras-chave: Nietzsche - Wagner - Zaratustra - Parsifal filosofia da arte-Quellenforschung.

1.

Provavelmente hoje é impossível entender completamente o que Richard Wagner significou para Nietzsche. Não somente porque, por maior que seja o conjunto de documentos e de notícias disponíveis sobre a relação deles, os relacionamentos pessoais, ainda mais se profundos, possuem uma essência talvez não comunicável e sem dúvida não transmissível, mas também porque o nosso olhar histórico contém erros de perspectivas que devemos corrigir. Quando colocamos lado a lado os nomes de Nietzsche e de Wagner, enxergamos neles dois dos mais importantes personagens do século XIX e, na disputa entre eles, vemos o confronto de dois gigantes da cultura ocidental. Não foi isso que aconteceu, porém, na época.

Quando Nietzsche encontrou pessoalmente pela primeira vez Wagner ${ }^{1}$, no dia 8 de novembro de 1868, ele era um jovem e

\footnotetext{
* Pós-doutorando na Universidade do Oeste do Paraná, Unioeste, PR. Correio eletrônico: stefano.buselatto@email.it

1 A saborosa narrativa da primeira rocambolesca visita que Nietzsche fez a Wagner pode ser
} 
anônimo estudante de filologia clássica, com uma paixão tão forte pela música ao ponto de ter cogitado seguir a carreira de compositor, antes de submeter-se à vontade da mãe e à tradição familiar, inscrevendo-se na faculdade de teologia de Bonn². Ele tinha 24 anos. Wagner, ao contrário, tinha a mesma idade do falecido pai de Nietzsche e era o músico mais reconhecido da época, em um período em que a música, e especialmente a música alemã, era a arte-rainha da cultura europeia, no seu apogeu romântico, além de ser considerada a própria linguagem do absoluto, capaz de destruir os grilhões ilusórios da aparência, das palavras e da barreira de finitude que aprisiona o homem. A sua fama era tal que pouco tempo depois daquele encontro Wagner obteve o prestígio de ter um inteiro teatro projetado exclusivamente para a sua música, "a maior vitória que um artista já conquistou" (MA I/HH I, Prefácio, 1, KSA 2.13). Na vida de Nietzsche não houve nenhum outro encontro mais importante do que aquele com Wagner³.

É imprescindível considerar esse aspecto para conseguir entender o entusiasmo, o orgulho, a veneração que fizeram com que Nietzsche considerasse Wagner como "o meu Zeus"; as razões da partidária apologia wagneriana de $O$ nascimento da tragédia; o so-

lida na carta em que ele narra a "extraordinária história" a E. Rohde, no dia 9 de novembro de 1868 (EI, pp.644-649). Sobre o episódio, veja-se também M. Gregor-Dellin, Richard Wagner, R. Piper \& Co. Verlag, München, 1989; trad. it. (org.) B. Betti, Wagner, Rizzoli, Milano, 1983, pp. 501-505.

2 Falando sobre os seus anos de estudo, Nietzsche escreve: "Não se deram algumas circunstâncias casuais de caráter exterior; de outra forma, eu teria me arriscado a me tornar um músico [...] daquele momento em diante, no vazio que se criou, a filologia acabou se inserindo" (OFN, I/2, p. 504). Sobre a importância da música para Nietzsche no período pré-wagneriano, veja-se: S. Busellato, La musica in Nietzsche prima di Wagner. Un'evidenza trascurata, in «Annali della Facoltà di Lettere e Filosofia dell'Università di Siena», XXX (2009), pp. 189-209.

3 Ainda em Ecce Homo Nietzsche escreverá: “Agora que estou falando dos alívios da minha vida, preciso dizer uma palavra de gratidão por aquilo que nela representa o conforto mais profundo que estimo acima de todos os outros. E, com isso, me refiro sem dúvida à minha intimidade com Richard Wagner. Não me importo muito com todos os outros relacionamentos humanos; mas por nada na vida eu aceitaria tirar da minha vida os dias de Tribschen, os dias da confiança, da serenidade, dos casos sublimes - dos momentos profundos..." (EH/EH, Porque eu sou tão sagaz, 5, KSA 6.288).

Cad. Nietzsche, Guarulhos/Porto Seguro, v.38, n.1, janeiro/abril, 2017. |85 
frido Wagner a Bayreuth; os motivos que fizeram com que, até mesmo depois do rompimento entre os dois e também após a morte de Wagner, para Nietzsche ele continuou sendo uma questão insolúvel sobre a qual ele continuou voltando obsessivamente, e que o levou a concluir a própria produção intelectual com textos como Nietzsche contra Wagner e $O$ caso Wagner.

E apenas considerando tais fatos é possível medir a dimensão do ato de caráter e de autenticidade que Nietzsche demonstrou quando, depois de ter percebido as divergências filosóficas insanáveis que o separavam de Wagner ${ }^{4}$ e do mundo que ele representava, ele decidiu abandoná-lo, renunciando, assim, à estima, à consideração e à fama que a proximidade com Wagner lhe trazia, preferindo, ao invés disso, seguir um caminho autônomo e, à época, completamente anônimo.

Torna-se difícil compreender muitas páginas de Nietzsche sem conhecer Wagner, as suas obras de música e os seus escritos teóricos. Refletir sobre a relação que Nietzsche manteve constantemente com ele pode, ao contrário, abrir caminhos exegéticos sempre imprescindíveis e, às vezes, surpreendentes. Um dos elementos talvez mais importantes, e inexplicavelmente até hoje não contemplado pelos estudos nietzschianos, que conecta a obra de Nietzsche à influência de Richard Wagner, encontra-se exatamente no texto mais famoso de Nietzsche, Assim falou Zaratustra, obra que deve muito da própria origem e da sua forma ao Parsifal wagneriano. Por isso, analisar alguns dessas débitos pode fornecer elementos preciosos, ainda não explorados, para compreender um texto em tantos aspectos original e enigmático.

4 Ainda hoje, para explicar o afastamento de Nietzsche de Wagner, recorre-se às razões biográficas e psicológicas com maior frequência, ainda mais se morbosas, como a "ofensa mortal" de Wagner, que teria afirmado que a causa dos problemas de saúde de Nietzsche poderia ser o onanismo (cf. C.P. Janz, Friedrich Nietzsche. Biographie, Carl Hanser Verlag, München-Wien 1978-79; trad. it. M. Carpitella, Vita di Nietzsche, Laterza, Roma-Bari. 1980-82, II, pp. 74) quando, ao contrário, ainda que exista uma constelação complexa de razões, todas as motivações que podem ter sido de caráter biográfico e psicológico afundam na vastidão e na profundidade dos motivos essencialmente filosóficos e intelectuais que o próprio Nietzsche declara ad abundantiam. 
2 .

É necessário voltar ao período entre o outono de 1881 e o mês de fevereiro de 1883, isto é, desde a primeira vez em que o nome de Zaratustra aparece nas anotações nietzschianas - o fragmento póstumo 1 [195] no caderno M III/1 intitulado Meio dia e eternidade - até a conclusão da escritura da primeira parte de Zaratustra, finalizada em 14 de fevereiro de 1883. Nesse ínterim, ocorreu um evento cultural de repercussão mundial: a primeira execução do Parsifal, realizada no festival de Bayreuth em 26 de julho de 1882. É preciso, antes de tudo, corrigir um erro que quase todos os estudiosos cometem quando consideram, a essa altura cronológica, já arquivada no definitivo rompimento a relação de Nietzsche com Wagner $^{5}$. Não foi assim que Nietzsche viveu o acontecimento.

Os meses que antecedem o festival do Parsifal nos revelam, ao contrário, uma forte e nada reduzida esperança de restabelecer a relação, freada apenas pelo forte orgulho de não querer dar o primeiro passo. A quem lhe perguntava se ele estaria presente na estreia de Parsifal, Nietzsche respondia que ele não iria comparecer "exceto se Wagner me convidar pessoalmente (o que, de acordo com o meu conceito de 'alta oportunidade', é muito oportuno!). O meu direito a um lugar reservado não o coloco sequer em dúvida"6. Resposta que ele repetiu também à irmã que, ao contrário, participaria do evento: “Em relação ao convite a Bayreuth, que naturalmente está à sua disposição, [...] fico muito contente que você queira ir, você vai encontrar todos os meus amigos. Eu, porém, - me perdoe!

5 Em uma carta a Overbeck de alguns anos antes, podemos medir como Nietzsche vivia o afastamento de Wagner: "nada pode me ressarcir [...] o fato de ter perdido nos últimos anos a simpatia de Wagner. Quantas vezes eu sonho com ele, e ele sempre aparece como ele era quando nós tínhamos uma relação próxima! [...] Tudo isso agora passou - o que adianta ter razão contra ele em tantas coisas! Como se fosse suficiente para apagar da memória essa simpatia perdida. [...] ainda hoje [...] toda a minha filosofia vacila, e me parece uma loucura querer ter razão em troca do amor, e não poder comunicar o que se sente de mais precioso, para não destruir essa simpatia. Hinc meae lacrimae" (A. F. Overbeck, 20 de agosto de 1880, E IV, p. 34).

6 A I. Overbeck, 19 de janeiro de 1882, idem, p. 148. 
- não posso ir, exceto se Wagner me convidar pessoalmente e me tratar como o mais importante de todos os seus convidados".7.

É sem dúvida devido a essa esperança persistente e ao fato de querer provocar um encontro casual que pudesse, de uma certa forma, restabelecer a relação com Wagner, mas sem precisar superar o próprio orgulho, que podemos explicar a misteriosa viagem que Nietzsche decidiu realizar, de repente e em condições rocambolescas $^{8}$, de Genova até Messina entre os dias 29 de março e $1^{\circ}$ de abril de 1882. Nietzsche provavelmente soube que Wagner estava na Sicília, em Palermo, terminando a composição da partitura do Parsifal. E Wagner também foi até Messina entre os dias 10 e 14 de abril. Como afirma o biógrafo Janz: "é quase um milagre que eles não tenham se encontrado"9.

Além disso, é necessário dizer que a estreia do Parsifal no Festival de 1882 representou apenas a última etapa da longa relação de Nietzsche com a obra de Wagner. O projeto do Parsifal foi meditado por Wagner durante muito tempo, pelo menos desde $1857^{10}$, e três anos antes de conhecer Nietzsche, em 1865, ele redigira para o rei Luís II da Baviera um minucioso resumo dramatúrgi-

7 A E. Nietzsche, 12 de fevereiro, idem, p. 155

8 "Nietzsche havia escolhido propositalmente a fórmula mais aventureira: com um pretexto digno de romance ele tinha conseguido convencer o capitão de uma nave cargueira siciliana a aceitá-lo a bordo como único passageiro" (Friedrich Nietzsches Briefe An Peter Gast. 1876-1889. Mit Anmerkungen Und Namen-Register, Insel Verlag, Leipzig 1908, p. 335).

9 C.P. Janz, Vita di Nietzsche, cit., II, p. 86. É significativo que o documento nietzschiano dessa viagem que chegou até nós seja em linguagem artística, os Idílios de Messina, a coletânea de poesias publicada pela primeira vez em uma revista (no número de março de 1882 da revista de Schmeitzner, como pode-se atestar pela carta enviada por Nietzsche a Paul Rée no dia 24 de maio de $1882, \boldsymbol{E}$ IV, p. 184), que em seguida foi publicada n'A Gaia ciência. Não podemos excluir a hipótese de que o título escolhido possa conter um eco wagneriano: basta pensar, de fato, que Nietzsche estava presente na casa de Wagner na manhã do natal de 1870, durante a estreia do Siegfried $\mathbf{I d} \boldsymbol{d} \boldsymbol{l l}$, que Wagner realizou para fazer uma surpresa a Cosima como presente de casamento e para celebrar o nascimento do primogênito Siegfried. Muitas das impressões daquela viagem nas áreas limítrofes à casa de Wagner podem ser encontradas na terceira parte de Assim falou Zaratustra, nos capítulos O viajante, Sobre a visão e o enigma e Sobre a beatitude não desejada (cf. E IV, Notícias e notas, p. 676).

10 E. Newman, Wagner Nights, trad. it. (org.) D. Spini, Castelvecchi, Roma, 2013, p. 630. A 
co, que continha integralmente a versão realizada em 1882, na esperança de obter um financiamento ${ }^{11}$. No período em que Nietzsche e Wagner se encontravam com frequência, o projeto do Parsifal, portanto, já estava delineado com exatidão.

Mas há ainda mais. Se aquilo que atraiu Nietzsche durante seu primeiro contato com Wagner foi o mundo de Schopenhauer, - "em Wagner eu gosto das mesmas coisas que gosto em Schopenhauer: o sopro ético, o perfume faustiano, a cruz, a morte, o túmulo etc."12 -, em seguida, o romantismo inflado e decadente por meio do qual tornava-se possível uma retomada estética dos símbolos e dos valores cristãos, de outra forma teologicamente perdidos, fizeram com que ele, à medida que rejeitava progressivamente e com rapidez tal visão, rapidamente decidisse se afastar de Wagner e do obscurantismo do qual a sua música se fizera suasória apologia e veículo de proselitismo ${ }^{13}$. O Parsifal foi o apogeu de tudo isso em termos de música, a obra que mais do que qualquer outra celebrava grandiosamente os incensos e os êxtases. Por isso, para Nietzsche o Parsifal adquiriu o valor simbólico da honestidade e da obrigatoriedade de abandonar os passos de Wagner para seguir o próprio caminho autônomo e oposto quando, em 1878, (ou seja, depois do afastamento no festival de estreia de Bayreuth de 1876), Wagner

primeira leitura dos poemas de Wolfram von Eschenbach, "na edição crítica de Simrock e San Marte" em que Wagner encontrou o personagem do Parsifal, é de 1845, como ele mesmo narra em Mein Leben, a própria autobiografia que começa no ano do nascimento em 1864, publicada em 1870 e que Nietzsche conhecia muito bem, pois corrigiu os rascunhos e seguiu a fase de impressão. O trecho se encontra na edição italiana organizada por M. Mila, R. Wagner, La mia vita [1953], EDT, Torino, p. 219.

11 R. Wagner, Sämtliche Werke, XI: Dokumente zur Entstehung und ersten Aufführung des Bünenweihfestspiels Parsifal, hrgb. M. Geck, E. Voss, Schott, Mainz, 1970, pp. 45-74; A. Lorenz, Der musikalische Aufbau von Richard Wagner "Parsifal", Max Hesse, Berlin 1933, rist. Hans Schneider, Tutzig, 1966

12 Carta a Erwin Rodhe de 8 agosto de 1868, E I, p. 469.

13 Sobre isso, veja-se S. Busellato, Aimez-vous Brahms? I primi frammenti di Nietzsche contro Wagner e la vicenda del "Triumphlied", in M. C. Fornari (org.), Friedrich Nietzsche. Edizioni e interpretazioni. Atti del convegno omonimo, Lecce 24-26 marzo 2003, ETS, Pisa, 2007, pp. 123-153. 
lhe enviou o libreto definitivo do Parsifal e Nietzsche respondeu enviando-lhe o primeiro fruto da autonomia conquistada: uma cópia de Humano, demasiado humano.

3.

O que Nietzsche leu no libreto do Parsifal? Ele viu, ali, não apenas o fulcro dramatúrgico centrado na compaixão [Mitleid] schopenhaueriana ("sábio através da compaixão" [durch Mitleid wissen] é a marca de Parsifal ${ }^{14}$ ), mas sobretudo a manifestação de toda a simbologia cristã emoldurada na tríade das três virtudes teologais fé, amor e esperança: do "sagrado cálice" da última ceia que recolheu o sangue de Cristo à lança que feriu o Salvador; do rito eucarístico na primeira exposição do Graal no primeiro ato ao sinal da cruz de frente ao qual o castelo de Klingsor vem abaixo no segundo ato; do rito de batismo com a lavagem dos pés, unção da cabeça, aspersão e benção da Sexta-feira Santa no terceiro ato à pomba branca que pousa sobre a cabeça de Parsifal no final da ópera. Ele viu ali, colocados em música, conceitos como a angústia do pecado, o sofrimento da culpa, a condenação do "terrível desejo" de "tremendos instintos" sexuais, a dor da danação, o remorso, a assunção, a castidade, a penitência, a confissão, a expiação, a graça, a salvação, o êxtase e a redenção. Parsifal, um "estudante de teologia com uma formação de ensino médio": esse é o comentário cáustico que Nietzsche fez n'O caso Wagner.

Em Ecce homo ele conta o episódio do recebimento do libreto do Parsifal e do envio a Wagner de Humano, demasiado humano:

Quando eu finalmente tive em mãos o livro [Humano, demasiado humano], eu enviei [...] dois exemplares também para Bayreuth. Por uma coincidência milagrosamente significativa, ao mesmo tempo chegou

14 Sobre a influência de Schopenhauer em Wagner, veja-se B. Magee, The philosophy of Schopenhauer, Claredon Press, New York, 1983, pp. 350-402, sobre o Parsifal, pp. 395-402. 
até mim ${ }^{15}$ uma bela cópia do texto do Parsifal, com a dedicatória de Wagner para mim "ao seu caro amigo Friedrich Nietzsche, Richard Wagner, conselheiro eclesiástico". Esse entrecruzar-se de dois livros - me pareceu que tivesse o som de um presságio. Não soava como o entrecruzar-se de duas espadas?... De qualquer forma, ambos sentimos isso: porque nós dois ficamos em silêncio. - Nesse período, vieram à luz também os primeiros "Bayreuther Blätter": assim eu entendi para o quê havia chegado a hora. - Inacreditável! Wagner se tornou pio..." (EH/EH, Humano, demasiado humano 5, KSA 6.327, tradução levemente modificada pelo autor).

Mas essa não é a primeira vez em que ele fala sobre o "entrecruzar-se de espadas". Ele narra o episódio pela primeira vez em uma carta de resposta a Lou Salomé em 16 de julho de 1882, dez dias antes da estreia do Parsifal à qual ela estava se dirigindo, depois que ela lhe perguntara se ele também estaria presente. Nietzsche lhe diz:

Em relação a Bayreuth, estou feliz por não dever estar presente; todavia, se eu pudesse estar ao seu lado, como um espírito, sussurrando-lhe no ouvido isso e aquilo, então eu poderia suportar até mesmo a música do Parsifal (que para mim de outra forma é insuportável ${ }^{16}$ ). Eu gostaria

15 Que Nietzsche queira ter dado a isso um significado altamente simbólico a posteriori pode ser confirmado pelo fato de que não foi percebido pelos seus contemporâneos como um "caso milagroso": Nietzsche de fato recebeu o libreto do Parsifal em $1^{\circ}$ de janeiro de 1878 (KGB II/6/II, p. 788). Ele respondeu enviando um exemplar de Humano, demasiado humano apenas em abril, ou seja, quatro meses depois (carta a E. Schmeitzner, metade de abril de 1878, E II, p. 287).

16 Na verdade, Nietzsche gostou muito do Parsifal, como escreve comovido em uma carta a Köselitz de 21 de janeiro de 1887, depois de ter escutado o Vorspiel: "Quando eu encontrar o senhor novamente, lhe direi exatamente o que finalmente compreendi. Deixando de lado qualquer questão irrelevante (a qual finalidade a música pode ou deveria servir?) e falando exclusivamente de um ponto de vista estético, eu me pergunto: Wagner alguma vez fez algo mais belo? [...] aqui, justo na profundidade dessa música, transparece um sentimento sublime e extraordinário, uma experiência de vida e um êxito da alma que honram muito o nome de Wagner, uma síntese de estados de espírito que muita gente, incluindo os nossos intelectuais "superiores", irá considerar incompatível: uma tremenda rigorosidade "do alto" que deriva de uma compreensão profunda da alma e que vê através da alma, atravessando-a como o fio de uma navalha, e ao mesmo tempo com isso há também uma compaixão por aquilo que foi

Cad. Nietzsche, Guarulhos/Porto Seguro, v.38, n.1, janeiro/abril, 2017.|91 
que você lesse o meu breve ensaio Richard Wagner em Bayreuth [...]. Eu tive muitas experiências em relação a esse homem e à sua arte foi uma longuíssima PAIX̃̃o: eu não saberia defini-la de outra forma. A renúncia que aqui é pedida, a necessidade, que se tornou enfim inevitável, de reencontrar a mim mesmo, são algumas das coisas mais duras e melancólicas do meu destino. As últimas palavras que Wagner me escreveu estão em um belo exemplar com dedicatória do Parsifal: "Ao meu caro amigo Friedrich Nietzsche. Richard Wagner, conselheiro eclesiástico". Ao mesmo tempo chegou até ele, enviado por mim, o livro Humano, demasiado humano - e com isso tudo ficou claro, mas tudo também acabou ${ }^{17}$.

Nietzsche não quis assistir ao festival parsifaliano, mas na noite anterior à partida da irmã para Bayreuth ele compensou sua ausência dedicando-se ao estudo da partitura da ópera. Seria espontâneo da nossa parte esperar, como resultado desse estudo, uma crítica feroz da obra e a continuação da metáfora do duelo de duas visões opostas em rota de colisão. O que encontramos, pelo contrário, na análise de Nietzsche é surpreendente. Ele escreveu ao amigo, também músico, Köselitz:

Domingo eu fui a Naumburg para preparar um pouco a minha irmã ao Parsifal. E me aconteceu algo bastante estranho! No final eu lhe disse: "Querida irmã, quando eu era jovem e eu escrevia música, no Oratório eu fazia exatamente esse gênero de música"18

percebido e julgado. Só Dante é comparável, ninguém mais. Já existiu algum pintor capaz de descrever de forma tão triste uma visão do amor como Wagner fez nos acentos finais do seu Prelúdio?" ( E V, pp. 312-313). Ainda dando os últimos conselhos à irmã que estava prestes a se dirigir à primeira execução do Parsifal com Salomé, Nietzsche escreve: "Não esqueça que quem volta de Bayreuth sem ter experimentado alguns instantes e sensações de sublime torna inútil o fato de ter ido até lá” (A Elisabeth Nietzsche, 28 de julho de 1882, E IV, p. 219).

17 Carta enviada a L. von Salomé, 16 de julho de 1882, E IV, p. 216.

18 Trata-se da longa composição Weihnachtsoratorium, obra bem realizada, mas que é apenas um esboço, cuja partitura pode ser lida em C. P. Janz, Der musikalische Nachlaß, Bärenreiter, Basel 1976, pp. 254-297, na qual, na verdade, é muito difícil encontrar os acentos parsifalianos, pois ela parece se orientar mais na direção da obra de Brahms. E tal fato daria também à comparação um sabor irônico (cf. S. Busellato, Aimez-vous Brahms?..., op. cit.). 
- e então eu busquei as velhas páginas e, depois de tanto tempo, eu as toquei de novo: a identidade de inspiração e de expressão era fantástica! Além disso, alguns trechos, por exemplo A morte dos reis, pareceram-nos mais tocantes do que tudo o que havíamos tocado do Parsifal, mesmo que fossem totalmente parsifalescos! Eu confesso: com verdadeiro assombro eu voltei a perceber quanta afinidade eu tenho no profundo com Wagner"19.

Nessa comparação feita por Nietzsche entre o Parsifal e o próprio oratório juvenil, gênero não litúrgico, mas sacro e dramático, em muitos aspectos portanto realmente próximo à obra wagneriana (Ein Bühnenweihfestspiel [Uma ação cênica sacra] é o subtítulo do Parsifal), podemos identificar duas atitudes psicológicas concomitantes, porém opostas. De um lado, a busca de uma proximidade e de uma íntima união com Wagner e com a sua última criação; do outro, o desejo de marcar ao mesmo tempo a distância que o separava dele, desenhando direções opostas no mesmo caminho: um Wagner que, na última fase da sua vida, regride à imaturidade religiosa da qual Nietzsche, amadurecendo, tinha se emancipado.

4.

Mas para completar o quadro do período no qual começa a tomar forma a ideia do Zaratustra, há ainda outro elemento que precisa ser levado em consideração. Estamos, de fato, no mesmo período em que Nietzsche procura com maior convicção uma alternativa artístico-musical a Wagner e vê essa possibilidade tomar corpo, inesperadamente, descobrindo Bizet e a sua Carmen. Em 7 de novembro de 1881, no teatro Paganini de Genova, Nietzsche se entusiasma por "François [sic] Bizet [...] nem um pouco desorientado por Wagner [...] eu não acreditava que algo desse gênero

19 Carta a H. Köselitz, 25 de julho de 1882, E IV, p. 218. 
fosse possível"20, e envia a partitura de Carmen, acompanhada com anotações nas margens, a Köselitz, que inicialmente não percebe a grandeza do músico. Entre elas, encontramos escrito: "Um epigrama sobre a paixão, o que de melhor foi escrito desde o tempo de sur l'amour de Stendhal", e comentando a parte de Micaëla no dueto com Don José Parle-moi de ma mère!, glosa: "Isso é o que Wolfram v. Eschembach [do qual Wagner extraiu o Parsifal] gostaria de ter cantado em louvor ao amor - mas ele não encontrou um modo para fazê-lo e teve que se contentar em expressar o seu desejo deste canto" ${ }^{\text {"21 }}$.

$\mathrm{O}$ que fez com que Nietzsche visse em Bizet uma alternativa estética a Wagner foi a escolha dos mesmos temas que este último estimava - o amor, a morte, a paixão, a liberdade -, mas com um tratamento oposto àquele wagneriano, isto é, sem, a sombra da moral wagneriana, sem pecado, culpa e expiação. É, ao contrário, música "má, refinada, fatalista" (WA/CW 1, KSA 6.13), música "além do bem e do mal", ao ponto de levá-lo a comentar à margem do excerto dos contrabandistas: "como se fosse uma parábola do Zaratustra"22, "Sobre a 'Felicidade dos maus' [Vom 'Glück der Bösen']"23.

Em Bizet Nietzsche sente que tudo é "mediterraneamente" paixão inocente; a profundidade, sedução; a morte, às vezes, limite extremo de uma exuberância que é vida e natureza, o contrário daquela "natureza desculpada [die entsündigte Natur]" apenas graças à obra do Redentor [Erlöser] que encontramos no III ato do Parsifal: Carmen, a antípoda de Kundry.

É de conhecimento geral que depois Nietzsche admitiu que a contraposição de Bizet a Wagner foi apenas uma "antítese irônica”,

20 Carta a H. Köselitz, 28 de novembro de 1881, E II, p. 74.

21 As anotações se encontram respectivamente nas páginas 4 e 64 da partitura conservada no Goethe-und-Schiller-Archiv. Para uma análise dos comentários de Nietzsche sobre a partitura de Carmen, P. D'Iorio, Nietzsche tra Tristano e Carmen in C. Tatasciore, Filosofia e musica, Bruno Mondadori, Torino, 2008, pp. 117-132; Id., En marge à Carmen, in "Magazine littéraire", n. 383 (Nietzsche. Contre le nihilisme), janvier, 2000, pp. 50-55.

22 P. D'Torio, Nietzsche tra Tristano e Carmen, cit., p. 124.

23 P. 273 da partitura de Carmen.

94| Cad. Nietzsche, Guarulhos/Porto Seguro, v.38, n.1, janeiro/abril, 2017. 
ditada pelo fato de que teria sido "uma falta de esmero sem igual se eu tivesse iniciado com Beethoven" 24 . Mas o que permanece é a vontade, no período de ideação do Zaratustra, de encontrar uma antítese artística aos valores celebrados por Wagner que atingiram o grau supremo com o drama sacro parsifaliano.

5.

Considerando os elementos até aqui analisados, podemos, portanto, formular uma hipótese até agora inexplorada, quer dizer, o fato de que existe uma ligação direta entre o Parsifal e a decisão de escrever o Zaratustra.

Se é verdade que no período entre a primeira aparição do nome de Zaratustra nos cadernos nietzschianos, no verão de 1881, e o começo do verdadeiro trabalho de composição do texto, que se pode datar no verão de 1883, encontram-se a relação com Lou Salomé e a esperança não realizada de encontrar nela uma discípula para a própria filosofia, e se é plausível que um dos moventes à elaboração do Zaratustra foi ter nascido como provável reação psicológica à tal decepção, pela vontade de tornar-se mestre, ele mesmo, do próprio pensamento, criando para si um público de hipotéticos alunos no porvir a partir da figura do sábio persiano, assim, devemos perceber da mesma forma a importância do fato de que também nesse período encontra-se a estreia do Parsifal, com tudo aquilo que a precede, como vimos: a relação não resolvida com Wagner, o significado simbólico que o Parsifal tinha para Nietzsche, o "entrecruzar-se de duas espadas", o paralelismo com a ingênua cristandade juvenil do próprio Oratório, a busca por uma alternativa estética a Wagner via Bizet.

Portanto, entre as razões decisivas que levaram ao nascimen-

24 Carta de C. Fuchs, 27 de dezembro de 1888, $E$ V, p. 574. Sobre a relação entre Nietzsche, Bizet, a Carmen, o Parsifal e a influência de Liszt nessa última obra, veja-se o ensaio, em outros aspectos discutível, de M. Bortolotto, Altra aurora, in F. Nietzsche, Scritti su Wagner, Adelphi, Milano, 1979, pp. 11-68, em particular as páginas 35-46. 
to de Zaratustra e aos excêntricos lineamentos do texto, é possível inserir também a escolha de se confrontar diretamente com o Parsifal, de criar uma espécie de anti-Parsifal, pelo desejo de voltar a entrecruzar as espadas enfrentando a mesma obra que simbolizou o seu afastamento de Wagner e de entrar conscientemente no mesmo terreno wagneriano, não no campo da teorético, mas no campo artístico - dando vida, assim, a um texto que veiculasse, por meio de artifícios estéticos, uma visão contrária àquela que se difundia com a sedução tão regressiva da partitura do "velho mago".

Um indício de tudo isso pode ser encontrado no texto escrito durante o período em análise e que precede Parsifal e Zaratustra. Em A gaia ciência, no aforisma 106, Nietzsche escreve:

"Tenho sede de um mestre na arte musical", disse um inovador ao seu discípulo, "que aprendesse os meus pensamentos e que os traduzisse, em seguida, na sua linguagem: assim seria mais fácil para mim me insinuar no ouvido e no coração dos homens. Os homens podem ser seduzidos com os sons a qualquer erro e a qualquer verdade: quem poderia confutar um som?" $\left(F W / G C\right.$ 106, KSA 3.463) ${ }^{25}$.

Sabe-se que a figura do Zaratustra fez a sua primeira aparição no célebre aforisma 125 de A gaia ciência sobre a morte de Deus, cuja elaboração preparatória trazia ao invés de "o homem louco" o nome, em seguida apagado, de "Zaratustra". Menos conhecido, porém, é o fato de que a mesma coisa acontecera antes nesse aforisma, cuja primeira versão apresentava o nome de Zaratustra no lugar do "inovador"26.

25 Podemos ver uma repercussão de tal aspiração nietzschiana na preocupação de que o $\mathbf{Z} \boldsymbol{a}$ ratustra não fosse entendido e recebido como uma mera obra literária: "Sinto desprezo pela ideia de que o Zaratustra entre no mundo como literatura de entretenimento; quem é sério o suficiente para isso! Se eu tivesse a autoridade do "último Wagner", as coisas tomariam uma direção melhor. Mas agora ninguém me pode salvar do perigo de ser jogado às traças no canto dos "literatos". Que nojo!" (Carta a Köselitz, 6 de abril de 1883, E IV, p. 338).

26 Para um aprofundamento desse aforisma como pré-anúncio da problemática do Zaratus- 
De tal modo, voltando à primeira anotação em que encontramos o nome de Zaratustra, a 1 [195], do verão-outono de 1881, e observando-a em conjunto com a partitura do Parsifal, podemos entrever algumas motivações que podem ter chamado a atenção de Nietzsche sobre o trecho que constitui a fonte originária da ideia do Zaratustra ${ }^{27}$.

Trata-se de um texto de história das religiões de Friedrich Anton von Hellwand, Culturgeschichte in ihrer natürlichen Entwicklung bis zur Gegenwart (Hamburg, Lampart \& Comp. 1875). Aqui, tendo chegado na página 128, Nietzsche encontra a figura do fundador persiano do zoroastrismo e copia o trecho inicial, que será praticamente idêntico ao incipit de Assim falou Zaratustra ("Tendo completado trinta anos, Zaratustra abandonou o seu vilarejo..."). A partir da leitura dessa página, pode ter nascido a ideia de escrever um texto que criasse parodicamente, por meio de uma voz pagã, o mesmo hieratismo que acomuna Zaratustra e Parsifal e que, por meio dos mesmos instrumentos retóricos da arte, divulgasse a própria anti-metafísica, a boa nova da imanência radical, do "eu vos imploro, irmãos, permaneceis fiéis à terra" (Za/ZA I, Prefácio, 3, KSA 4.14).

Temos evidências, de fato, para supor que a escolha do personagem persa não seja de forma alguma fruto de uma inspiração repentina se pensarmos que, como Nietzsche sabia desde os tempos da leitura do libreto, também é persa a etimologia que Wagner acreditava dar vida ao nome de Parsifal: Fal Parsi, o puro louco,

tra, veja-se S. Busellato, Tre antecedenti di Zarathustra nell'opera di Nietzsche: WS 84, WS 213, FW 106 em publicação.

270 mérito da individuação de tal fonte é de P. D’Iorio, Genèse, parodie et modernité dans "Ainsi parlait Zarathoustra", in Gilbert Merlio (éd.), Ainsi parlait Zarathoustra, Paris, Éditions du Temps, 2000, pp. 25-43. Cf. anche P. D’Iorio, «Beiträge zur Quellenforschung», Nietzsche-Studien, XXII (1993), pp. 395-402. D’Iorio supera, a partir de um confronto textual que não deixa dúvidas, a precedente hipótese de M. Montinari que havia pensado que Nietzsche pudesse ter encontrado o personagem do Zaratustra nos Essays de R. W. Emerson (KSA XIV, p. 279) baseando-se no caderno MIII7 do começo de 1882 que contém um estudo do texto do americano (OFN V/2, pp. 556-558). 
como é revelado por Kundry no II ato ${ }^{28}$.

Ainda na relação de competição com Wagner podemos encontrar, também, as razões pelas quais Nietzsche se dirige ao Oriente para criar o próprio anti-Parsifal. Se Köselitz, quando recebe a III parte do Zaratustra, presta particular atenção ao sabor de religiosidade oriental de Assim falou Zaratustra ${ }^{29}$, ele parece não perceber que ele mesmo, inconscientemente, pode ter orientado Nietzsche a seguir aquela direção. Um documento praticamente ignorado pelos estudos nietzschianos é uma longa carta em que Köselitz, comentando tecnicamente o Parsifal, relata a Nietzsche a intenção de Wagner de escrever uma nova ópera, mais uma vez de tema religioso, Der Sieger, mas com tema oriental, tendo como protagonista Ananda, discípulo de Buda, tornando ainda mais forte o nó religioso-schopenhaueriano tão detestado por Nietzsche, com a intenção de colocar em cena um "homem totalmente livre de qualquer paixão"30.

28 Wagner encontrou essa etimologia, que se revelou errônea, no prefácio de Lohengrin de Joseph Görres. Ele a explica em uma carta de 1877 à filha de Théophile Gautier: "Ce nom est arabe [...] "Parsi fal" signifie: "parsi" - pensez aux Parses adorateurs du feu - "pur"; "fal" dit "fou", dans un sens élevé, c'est à dire homme sans érudition, mais de génie ("Fellow", en anglais, paraît être en rapport avec cette racine orientale)" (cit. in R. Wagner, Dokumente zur Entstehung und ersten Aufführung des Bünenweihfestspiels, cit., p. 26). Sobre essa questão, veja-se M. Unger, The cradle of the Parsifal Legend, A speculative theory that the legend originated in Persia, supported by mistranslation of Persian sources, in "Musical Quarterly", 1932, pp. 428-442.

29 "Ao lê-lo temos quase a sensação de que precisamos recomeçar a contar o tempo partindo dele. Um dia o senhor deverá ser venerado ainda mais do que os fundadores das religiões asiáticas e - precisamos esperar - de forma menos asiática" (H. Köselitz a Nietzsche, 29 de fevereiro de 1884, KGB III/2, p. 419).

30 Wesendonck-Briefe, in Richard Wagner an Mathilde Wesendonk: Tagebuchblätter und Briefe 1853-1871, W. Golther, Leipzig 1914, p. 108. Também O vencedor, assim como Parsifal, foi um projeto meditado durante muito tempo por Wagner. Dele possuímos um esboço dramatúrgico de 16 de maio de 1856 (para um aprofundamento: W. Osthoff, Richard Wagners Buddha-Projekt "Die Sieger". Seine ideellen und strukturellen Spuren in "Ring" und "Parsifal", in "Arkiv für Musikwissenschaft XL", 3, 1983, pp. 189-211). Wagner encontrou o personagem na Introduction à l'histoire du buddhisme indien de Eugène Burnouf, pela sugestão de Malwida von Meysenbug, a qual, não por acaso, conversando com Köselitz sobre Ananda, diz que ele é um "inteligente discípulo de Nietzsche-Buda (KGB III/2, p. 375). É também significativa a resposta que Nietzsche deu em uma outra troca de livros, quando ele recebeu de Paul Deussen o seu texto, Das System des Vedânta, quando Nietzsche tinha 
6.

Observando, assim, o Zaratustra sob essa perspectiva de oposição a Wagner e ao Parsifal, pode-se perceber que se abre um outro nível de intertextualidade e de significação nas definições que Nietzsche fornece do próprio texto, que revelam mais do que simples metáforas ou excessos do autor: ele fala de um "quinto "Evangelho"'31, de um "livro sagrado"'32, como ele repete a uma wagneriana convicta como Malwida von Meysenbug, "é um livro sério como qualquer outro livro sagrado, embora introduza o riso na religião"33. Aquilo que Wagner, com o "drama sacro" do Parsifal, revigorava e tratava de novo com a mais alta consideração, Nietzsche com o Zaratustra, usando o mesmo registro, queria inverter, por meio de uma paródia, para opor-lhe uma visão contrária.

Ainda mais interessante, - lembrando também o comentado aforisma 106 de A gaia ciência sobre o mestre de arte musical que seduz os homens "a qualquer erro e a qualquer verdade" -, é ler as definições musicais com que Nietzsche fala insistentemente da própria obra: "Talvez pode-se considerar como música todo o Zaratustra", em Zaratustra "a sentença [...] treme de paixão: a eloquência [...] se torna música" (EH/EH, Assim falou Zaratustra, 6 e 1, KSA 6.343/335); as comparações com o gênero musical mais anti-wagneriano, ou seja, a sinfonia ("como deve-se classificar com exatidão

acabado de terminar a primeira parte do Zaratustra: "O acaso quis que exatamente nesse momento estejam imprimindo o meu manifesto que, com eloquência praticamente idêntica à sua diz "sim" onde o seu livro diz "não". Há motivos para rir; mas talvez isso poderia te causar dor e ainda não sei se devo enviá-lo". (Carta a Paul Deussen, 16 de março de 1883, E IV, pp. $322-323)$.

31 Carta a Overbeck e a Schmeitzner, 10 e 13 de fevereiro de 1883, idem, p. 307. In WA§ 5, Nietzsche escreve: "A sua [de Wagner] força de sedução aumenta desproporcionalmente, em torno dele queima incenso, o erro de interpretação sobre ele chama-se "Evangelho"” $(W A / C W$, 5, KSA 6.21).

32 Carta a Köselitz, 21 de abril de 1883, E IV, p. 345.

33 Carta a M. von Meysenbug, 20 de abril de 1883, idem, p. 343. 
esse Zaratustra? Eu diria que quase entre as "sinfonias""34); o fato de vermos já no primeiro plano da ópera, no fragmento sucessivo à nota de leitura de Hellewand, o texto dividido em quatro "movimentos", cujo primeiro devia ser "no estilo do primeiro tempo da Nona Sinfonia"35; ou, ainda, o fato de ter considerado por muito tempo, ao contrário, o texto acabado em três partes, declarando: "O meu Zaratustra em três atos está concluído"36, assim como três também eram os atos do Parsifal.

No Parsifal, no seu "hegelismo em música"37, Nietzsche percebeu o perigo de um poder obscurantista dotado de uma atratividade sem igual, uma "possessão hipnótica [que] abate até mesmo os mais fortes como se fossem touros" (WA/CW 5, KSA 6.21). Por isso, em um fragmento de 1888 ele reconhece a si mesmo o mérito de ter reconhecido no Parsifal "o desvio [...], o caminho na direção do nada que ele conseguiu fazer com que acreditassem que fosse o caminho até a divindade (Nachlass/FP 15 [17], primavera de 1888, ksa 13.416)". "A sua última ópera é, nesse sentido, a sua maior obra-prima. O Parsifal irá conservar pela eternidade o seu lugar na arte da sedução. Eu admiro essa obra, eu mesmo gostaria de tê-la realizada; na impossibilidade disso, eu a compreendo..." (WA/CW, Pos-escrito, KSA 6.40).

Compreendê-la significou reagir a ela. "Com o seu Parsifal,

34 Carta a H. Köselitz, 2 de abril de 1883, E IV, p. 333. Sobre a comparação entre Zaratustra e uma sinfonia, vejam-se também as cartas a Schmeitzner, de 18 de janeiro de 1884, idem, p. 442 e de 6 de fevereiro de 1884, idem, p. 449; a Overbeck, 6 de fevereiro de 1884, idem, p. 451; a Köselitz, 30 de março de 1884, idem, p. 446. Levando completamente a sério tal comparação com a sinfonia, C. P. Janz, Vita di Nietzsche, cit., pp. 190-200, aventura-se em uma tão fascinante quanto excessiva análise de todos os elementos em comum entre o Zaratustra e o gênero compositivo sinfônico.

35 FP 11 [197], primavera-outono de 1881. Também mais tarde encontramos planos em que Zaratustra è dividido em "atos", FP 13 [2], verão de 1883.

36 A E. Rodhe, 22 de fevereiro de 1884, $\boldsymbol{E}$ IV, p. 454.

37 A M. von Meysenbug, 13 de julho de 1882, idem, p. 174. Também além do Parsifal, sobre a acusação contra Wagner de que ele era o "herdeiro de Hegel" veja-se WACW 10, KSA 6.35.

100| Cad. Nietzsche, Guarulhos/Porto Seguro, v.38, n.1, janeiro/abril, 2017. 
[Wagner] exortou a alma moderna a todas as covardias" ${ }^{938}$. Com o $\mathrm{Za}$ ratustra, Nietzsche quis, então, criar uma sedução inversa, um texto anti-moderno, exortativo, protréptico, que através de meios artísticos incentivasse a modernidade a abandonar os perigos da décadence e a escolher o caminho oposto, ou seja, o da emancipação. Com "o meu filho Zaratustra [...] eu quero empurrar a humanidade a tomar decisões que determinem completamente o futuro humano"39.

Assim, na complexa riqueza de Assim falou Zaratustra, se seguirmos também a presença da vontade de se posicionar como anti-Parsifal, pode-se abrir, então, um caminho precioso para o exegeta, tanto no plano geral - no qual, assim, tornam-se menos misteriosas as razões da necessidade de fazer a própria filosofia se expressar por meio do canto da composição artística, que de outra forma pareceria ser repentina e incompreensível -, quanto em muitos particulares do texto, sobretudo na primeira parte que, como o acaso quis, confirmando o seu simbolismo extremo, Nietzsche publicou em 14 de fevereiro de 1884, na mesma "ora sagrada em que Richard Wagner morreu em Veneza" (EH/EH, Assim falou Zaratustra, 1, KSA 6.335$)^{40}$.

7.

Considerando o Parsifal como "drama da compaixão"41, no qual Mitleid se torna a "palavra-chave", lê-se sob luzes diferentes, por exemplo, a insistência sobre o valor negativo da compaixão, a apologia do egoísmo (Za/ZA, III, "Sobre as três coisas más", KSA 4.235), o discurso da segunda parte do Zaratustra "Dos compassivos" [Von der Mitleidigen]. Conhecendo o segundo ato do Parsifal e a cena das Blümenmädchen [Meninas-flor], é possível vê-la invertida no "Canto de dança", em que Zaratustra chega em um "verde campo [...] em que

38 Nachlass/FP 14 [52], primavera de 1888, KSA13.243.

39 Carta a M. von Meysenbug, primeiros dias de maio de 1884, E IV, pp. 475-476.

40 Na verdade Wagner morreu em 13 de fevereiro, mas Nietzsche recebeu a notícia no dia seguinte, mesmo dia em que enviou ao seu editor o texto da primeira parte do Zaratustra.

41 E. Newman, Wagner Nights, op. cit., pp. 701-702. 
meninas dançavam" [auf der tanzten Mädchen]. Conhecendo o comentário cáustico sobre a apologia parsifaliana da castidade [Keuschheit] ("Wagnerus dixit princeps in castitate auctoritas", WA/CW 9, KSA 6.32) e o comentário na terceira dissertação da Genealogia da moral ("O sermão sobre a castidade permanece uma instigação à negação da natureza: eu desprezo qualquer pessoa que não sinta no Parsifal um atentado à ética", GM/GM, III, 3, KSA 5.341), o trecho da primeira parte do Zaratustra "Da castidade" [Von der Keuschheit] irá se revelar aos nossos olhos a partir de um novo ângulo. Nesta passagem é proclamada a "inocência dos sentidos" [Unschuld der Sinne], enquanto Klingsor ao contrário se castra para reduzir "a um silêncio mortal" os "tremendos instintos" [schrecklichster Triebe]. Lembrando o primeiro comentário depois do recebimento do libreto parsifaliano ("Inacreditável! Wagner se tornou pio...") e a referência ao próprio oratório juvenil na ocasião em que estudou a partitura da obra, é possível compreender por que o primeiro personagem que Zaratustra encontra é um santo ancião que ao ver Zaratustra afirma: "Então é possível! Esse velho santo na sua floresta ainda não soube que Deus está morto" (Za/ZA I, Prefácio, 2, KSA 4.12). E ganha outro sabor, se confrontado com o Parsifal elevado ao status de Redentor [Erlöser] por Wagner, ler no discurso "Da redenção" [Von der Erlösung], em que Zaratustra, tecendo uma refinada crítica aos fundamentos estéticos do tardo-romantismo wagneriano ${ }^{42}$, apresenta-se como um modelo de uma redenção alternativa, contrária ao "espírito de vingança", como "redentor da casualidade" [Erlöser des Zufalls]: "redimir aqueles que já passaram e transformar cada "assim foi" em um "assim eu quis que fosse" - só isso pode ser para mim a redenção!” (Za/ZA, Da redenção, KSA 4.177).

Nietzsche diversas vezes fala com desprezo e ironia sobre a redenção parsifaliana. As últimas palavras que Wagner escreveu em música foram "Milagre da mais alta salvação! Redenção ao Redentor!" [Höchsten Heiles Wunder! Erlösung dem Erlöser!]. Depois

42 Confronte-se o discurso de Zaratustra com as observações que Nietzsche deixou sobre o estilo da décadence romântica em $\mathrm{O}$ caso Wagner (WA/CW 6 e sobretudo em 7, KSA 6.23/26). 
dessas palavras desce o pano sobre o Parsifal. Para Nietzsche essa frase se tornou a essência do inteiro Parsifal, assim como também do seu autor ${ }^{43}$.

No "Pós-escrito" de $O$ caso Wagner, Nietzsche cunhou como epítome da própria oposição a Wagner a inversão da frase parsifaliana: "Redenção do Redentor!" Nietzsche escreve: "Se Wagner pôde se tornar o redentor: quem nos redime dessa redenção? Quem nos redime desse redentor?" (Nachlass/FP 14 [52] começo de 1888, KSA, KSA13.243). Mas relendo um dos primeiros cadernos que registram o começo da escritura do Zaratustra já é possível encontrar uma resposta a tal pergunta: "Zaratustra ensina a redenção de todos os redentores" (Nachlass/FP 9 [36], maio-junho de 1883, KSA 10.357, OFN VII/1/II, p. 13).

Levando a sério essa fugaz indicação deixada nas primeiras frases dos trabalhos zaratustrianos sobre a vontade de se colocar como anti-Parsifal é possível, portanto, seguir um caminho exegético promissor capaz de trazer à luz muitos aspectos de Assim falou Zaratustra que de outra forma estariam destinados a permanecer irremediavelmente opacos.

\begin{abstract}
Among the reasons for Nietzsche's composition of Zarathustra, one of aspects that have been majorly neglected by scholarly research concerns Richard Wagner and his Parsifal. This paper will explore a few significant details, that will be able to present a deep correlation between the two works. Such correlation could really cast some light on Zarathustra and its highly enigmatic style and contents. Indeed, it could propose new interpretative perspectives, that would be both original and helpful for an exhaustiveunderstanding of Nietzsche's work.

KeyWords: Nietzsche - Wagner - Zarathustra - Parsifal Philosopy of art - Quellenforschung.
\end{abstract}

43 Vejam-se Nachlass/FP $9[14,56]$ maio-junho de1883, ksa 10.349/364; FP 13 [1] verão de 1883, KSA 10.415; 41 [2] agosto-setembro de 1885, KSA 11.669, e as cartas a H. Köselitz dos dias 11 e 24 de agosto de 1888 (E V, p. 702 p. 711).

44 A primeira ocorrência publicada dessa locução aparece, não por caso, no discurso "Sobre os padres" da segunda parte de Assim falou Zaratustra (Za/ZA, Dos Sacerdotes, KSA 4.117). 


\section{Referências bibliográficas}

Bortolotтo M. “Altra aurora”. In: F. Nietzsche. Scritti su Wagner, Milano: Adelphi , 1979, pp. 11-68.

Busellato S. "Aimez-vous Brahms? I primi frammenti di Nietzsche contro Wagner e la vicenda del 'Triumphlied"'. In: M. C. Fornari (org.), Friedrich Nietzsche. Edizioni e interpretazioni. Atti del convegno omonimo, Lecce 24-26 marzo 2003, ETS, Pisa, 2007, pp. 123-153.

. "La musica in Nietzsche prima di Wagner. Un'evidenza trascurata". In: Annali della Facoltà di Lettere e Filosofia dell'Università di Siena, XXX (2009), pp. 189-209.

D’Torio P. "Genèse, parodie et modernité dans “Ainsi parlait Zarathoustra"'. In: Gilbert Merlio (éd.), Ainsi parlait Zarathoustra, Paris, Éditions du Temps, 2000, pp. 25-43.

. "Beiträge zur Quellenforschung”. In: Nietzsche-Studien, XXII (1993), pp. 395-402

. "Nietzsche tra Tristano e Carmen". In: C. Tatasciore. Filosofia e musica. Torino: Bruno Mondadori, 2008, pp. 117-132;

. "En marge à Carmen”. In: Magazine littéraire, n. 383 (Nietzsche. Contre le nihilisme), janvier, 2000, pp. 50-55.

Gregor-Dellin M. Richard Wagner. München: R. Piper \& Co. Verlag, 1989; trad. it. (org.) B. Betti, Wagner, Rizzoli, Milano, 1983.

JANZ C.P., Friedrich Nietzsche. Biographie, Carl Hanser Verlag, München-Wien 1978-79; trad. it. M. Carpitella, Vita di Nietzsche, Laterza, Roma-Bari. 1980-82.

. Der musikalische Nachlaß. Basel: Bärenreiter, 1976.

Lorenz A. Der musikalische Aufbau von Richard Wagner "Parsifal". Berlin: Max Hesse, 1933, rist. Hans Schneider, Tutzig, 1966.

Magee B. The philosophy of Schopenhauer. New York: Claredon Press, 1983.

Newman E. Wagner Nights, trad. it. (org.) D. Spini. Roma: Castelvecchi, 2013.

NiETzsche F. Kritische Gesamtausgabe, Werke, a cura di G. Colli e M. Montinari. Berlin: de Gruyter, 1967 e sgg.; ed. it. Opere di Friedrich Nietzsche, condotta sul testo critico originale stabilito da G. Colli e M. Montinari, Adelphi, Milano 1964 e sgg.

. Briefwechsel, Kritische Gesamtausgabe, a cura di G. Colli e M. Montinari. Berlin-New York: de Gruyter, 1975 ssg.; ed. it. parz. Friedrich Nietzsche. Epistolario condotta sul testo critico originale stabilito da G. Colli e M. Montinari, Adelphi, Milano 1976 e sgg.

Briefe An Peter Gast. 1876-1889. Mit Anmerkungen Und Namen-Register. Leipzig: Insel Verlag, 1908.

104| Cad. Nietzsche, Guarulhos/Porto Seguro, v.38, n.1, janeiro/abril, 2017. 
Osthoff W. "Richard Wagners Buddha-Projekt 'Die Sieger'. Seine ideellen und strukturellen Spuren in 'Ring' und 'Parsifal'”. In: Arkiv für Musikwissenschaft XL, 3, 1983, pp. 189-211.

WAGNER, R. Richard Wagner an Mathilde Wesendonk: Tagebuchblätter und Briefe 1853-1871. Leipzig: W. Golther, 1914.

Sämtliche Werke, XI: Dokumente zur Entstehung und ersten Aufführung des Bünenweihfestspiels Parsifal, hrgb. Mainz: M. Geck, E. Voss, Schott, 1970.

Unger M. "The cradle of the Parsifal Legend. A speculative theory that the legend originated in Persia, supported by mistranslation of Persian sources". In : "Musical Quarterly", 1932, pp. 428-442.

Artigo recebido para publicação em 15/07/2016. Artigo aceito para publicação em 10/10/2016. 